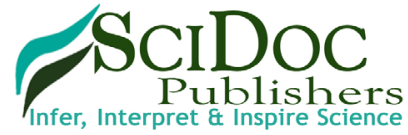

\title{
A First Case Description of Adrenal Gland Tumour in a Lion (Panthera Leo): Tomographic and Clinico-Pathological Findings
}

\author{
Case Report
}

\author{
Longo $\mathrm{M}^{1 *}$, Ravasio $\mathrm{G}^{1}$, De Zani $\mathrm{D}^{1}$, Rabbogliatti $\mathrm{V}^{1}$, Giordano $\mathrm{A}^{1}$, Paltrinieri $\mathrm{S}^{1}$, Andolfatto $\mathrm{A}^{2}$, Magnone $\mathrm{W}^{3}$, Di Giancamillo $\mathrm{M}^{1}$, Zani $\mathrm{DD}^{1}$
}

${ }^{1}$ Department of Veterinary Sciences and Public Health (DIVET), Azienda Polo Veterinario di Lodi, Università degli Studi di Milano, via dell’ Università n.6, 26900 Lodi (LO), Italy.

${ }^{2}$ Parco Safari delle Langhe, Frazione Rea 12060, Murazzano (CN), Italy.

${ }^{3}$ Parco Natura Viva, Località Figara n.40, 37012 Bussolengo (VR), Italy.

\section{Abstract}

An 8-year-old male lion with progressive lack of secondary sex characteristics, dysorexia and weight loss was referred to our Institution. The patient was anaesthetized to undergo general clinical evaluation, hematologic, serum biochemical and hormonal profile, FIV/FeLV tests. Total body computed tomography, abdominal ultrasonography and fine-needle aspirates of the liver and left adrenal lesion were performed. Imaging findings showed the presence of a neoplastic lesion on the left adrenal gland and generalized hepatopathy. Blood tests reported an estradiol concentration of $462 \mathrm{ng} / \mathrm{dl}$. To our knowledge, this is the first description of an adrenal mass in a lion associated with secondary feminization.

Keywords: Estradiol; Estrogen-Secreting Tumour; Feminizing Adrenal Tumour (FAT); Lion; Panthera Leo.

\section{Introduction}

A captive born intact male, eight-year-old, $130 \mathrm{~kg}$ body weight, Panthera leo was referred for a diffused lack of secondary sex characteristics with mane loss and testicular hypotrophy, alopecia, dysorexia, swollen abdomen and weight loss (approximately 50 $\mathrm{kg}$. in the last two months).

\section{Case History}

The lion was sedated by tele-anaesthesia with dexmedetomidine $(5 \mathrm{mcg} / \mathrm{kg})$ and ketamine $(2 \mathrm{mg} / \mathrm{kg})$ combination. A complete clinical evaluation and subsequent abdominal ultrasound examination were performed by the referring veterinarian with no significant abnormalities reported. Blood was collected to perform a complete blood count, a basic serum chemistry panel (AST, ALT, Albumin, ALKP, GGT, Total Bilirubin, Cholesterol, Total Protein, Triglycerides, Glucose, Urea, Creatinine, Albumin, Globulin and $\mathrm{A} / \mathrm{G}$ ratio, $\mathrm{Ca}^{++}, \mathrm{P}, \mathrm{Na}^{+}, \mathrm{K}^{+}, \mathrm{Cl}^{-}$), and the measurement of serum concentrations of thyroxine (T4), cortisol and testosterone. Serum protein electrophoresis and Feline Immunodeficiency Virus (FIV)/Feline Leukemia Virus (FeLV) tests were also performed. Nevertheless, laboratory results were unremarkable. The patient was discharged in order to collect data from the examinations performed. Over the next three months, the patient did not show any significant improvement of the clinical condition with a severe anorexia, progressive weight loss and lethargy. Therefore, the patient was immobilised again with the same anaesthetic protocol and after the placement of a $18 \mathrm{G}$ catheter into the right cephalic vein, the patient was maintained deeply sedated until reaching the University Hospital - Azienda Polo Veterinario di Lodi. A constant rate infusion (CRI) was administered by infusion pumps at $6 \mathrm{mcg} / \mathrm{kg} / \mathrm{h}$ of dexmedetomidine, to achieve an adequate continuous sedation (approximately for 3 hours). At the arrival the CRI was stopped and an intravenous bolus of propofol $(\sim 0,5 \mathrm{mg} / \mathrm{kg})$ was administered in order to obtain orotracheal intubation; general anaesthesia was maintained by isoflurane in $100 \%$ oxygen to effect, on mechanical ventilation. The patient was placed in dorsal recumbency on the computed tomography (CT) table with the hindlimbs extended caudally. A complete CT examination of the abdomen was

\footnotetext{
*Corresponding Author:

Maurizio Longo,

Department of Veterinary Sciences and Public Health (DIVET), Azienda Polo Veterinario di Lodi, Università degli Studi di Milano, via dell’Università n.6, 26900 Lodi (LO), Italy. Tel: +390250331120

E-mail: maurizio.longo@unimi.it

Received: December 10, 2015

Accepted: January 21, 2016

Published: January 25, 2016

Citation: Longo M et al., (2016) A First Case Description of Adrenal Gland Tumour in a Lion (Panthera Leo): Tomographic and Clinico-Pathological Findings. Int J Vet Health Sci Res. 4(1), 82-85. doi: http://dx.doi.org/10.19070/2332-2748-1600020

Copyright: Longo $\mathbf{M}^{\odot}$ 2016. This is an open-access article distributed under the terms of the Creative Commons Attribution License, which permits unrestricted use, distribution and reproduction in any medium, provided the original author and source are credited.
} 
performed with $2.5 \mathrm{~mm}$ slice thickness, a pitch of $2.75,140 \mathrm{kV}$ and $280 \mathrm{~mA}$, before and after intravenous bolus administration of $150 \mathrm{ml}$ of Iohexol (Omnipaque ${ }^{\circledR} 350 \mathrm{mg} / \mathrm{ml}$, GE Healthcare Milano - Italy) at a rate of $5 \mathrm{ml} / \mathrm{sec}$, by a power injection system (Medrad Mark V Plus ${ }^{\circledR}$, Milano - Italy). CT scan revealed a large focal expansive and heterogeneous well-defined round lesion on the cranial pole of the left adrenal gland $(40 \times 39 \times 37 \mathrm{~mm})$ (Figure 1-2). This lesion presented mild peripheral enhancement on post-contrast sequences with heterogeneous content (24-45 $\mathrm{HU}$ ) (Figure 1-2). Concurrently, the right adrenal gland appeared smaller, with normal density values and $6 \mathrm{~mm}$ thick.

Due to a severe bradycardia (35-40 bpm) experienced by the patient while under anaesthesia, a nonuniform postcontrast arterial phase was displayed after contrast medium administration, with streamlining artifact in the aorta and subsequent poor intraarterial and intravenous contrast enhancement. Subsequently, an ultrasonographic examination of the abdomen was performed confirming the presence of the adrenal lesion that had clearly defined margins with an isoechoic peripheral pseudocapsule and hypoechoic heterogeneous content. No intra-lesional vascularization nor vascular invasion in the phrenico-abdominal vein and caudal vena cava was detected. Additional findings included a heterogeneous liver with multifocal hypoechoic lesions characterized by undefined margins and testicles that were smaller than expected in size (20 $\mathrm{mm}$ in long axis plane), with normal ellipsoid shape, echogenicity and appearance of the mediastinum testis. Blood samples were collected to measure the estradiol concentration (by chemiluminescence method) of the patient and to check if coagulation parameters were within normal limits. Fine-needle aspirations (FNABs) of the left adrenal gland and of the liver were performed with the patient under apnoea by mechanical ventilatory control. In order to perform a safe procedure, the patient was maintained in a supine recumbency and the left side of the abdomen was slightly oriented towards the operator that was positioned on the contralateral side. Liver
FNABs were also performed with this positioning, moving the probe closer to the left side of the liver to avoid puncture of the gallbladder. No complications occurred during this procedure. The patient was later discharged and maintained under CRI during the return travel.

Cytological evaluation confirmed the neuroendocrine origin of the lesion (Figure 3): on a hematic background, large round cells, single or rarely forming small groups, characterized by a mild anysocytosis. These cells had abundant cytoplasms, that were slightly basophilic and microvacuolized, and had indistinct cell borders. Nuclei were small, central or paracentral, round, with clumped chromatin and occasionally had prominent nucleoli. Rare binucleated cells were also present. The lack of evident signs of malignancy was consistent with the adenomatous nature of the lesion (Figure 3). The hepatic FNABs contained mostly normal hepatocytes or hepatocytes characterized by intracytoplasmic vacuoles of different size and/or granules of black pigment, likely consistent with cholestasis or lipofuscinosis (Figure 4). No neuroendocrine/neoplastic cells were found in the liver. All these findings were consistent with a degenerative hepatopathy. Results from serum chemistry showed an estradiol concentration of 462 $\mathrm{ng} / \mathrm{dL}$. A robot-assisted minimally invasive surgery was performed in order to remove the left adrenal gland. Histopathology performed after the surgery confirmed the presumed diagnosis of adrenal adenoma. The patient fully recovered after seven months from adrenalectomy, putting on weight and re-gaining secondary sex characteristics.

\section{Discussion}

Although, to our knowledge, no reference intervals for the concentration of serum estradiol in Panthera leo have ever been published, there are several papers on small animals showing the variability of such concentrations over time. In dogs normal

Figure 1. Post-contrast transverse image of the cranial abdomen (WW 350, WL 40). White arrow indicates the peripheral enhancement of the lesion on the left adrenal gland. White asterisk indicates the streamlining artifact in the aorta.

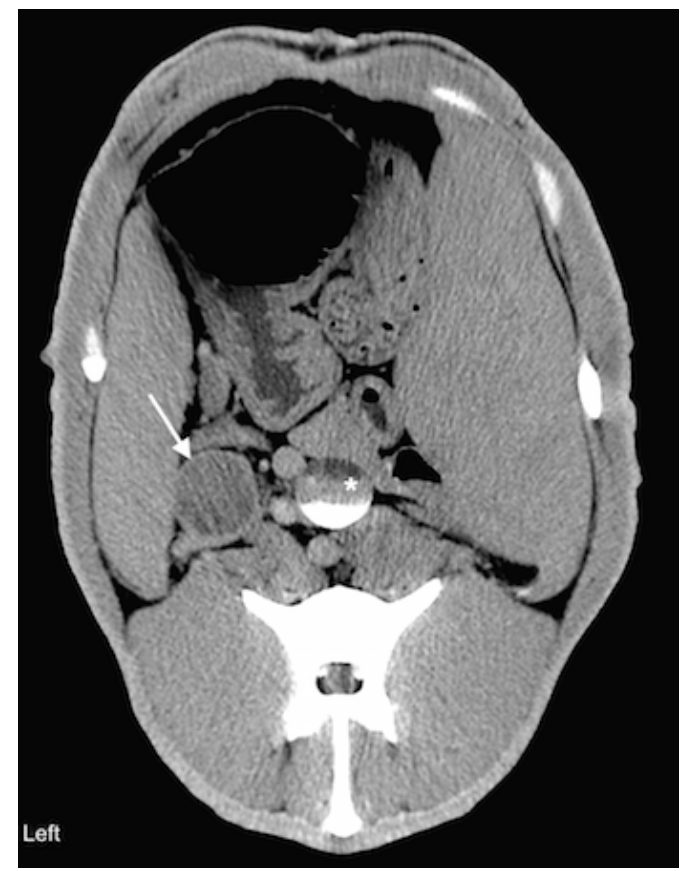


Figure 2. Post-contrast dorsal reconstruction of the cranial abdomen (WW 350, WL 40). White arrow indicates the lesion on the left adrenal gland.

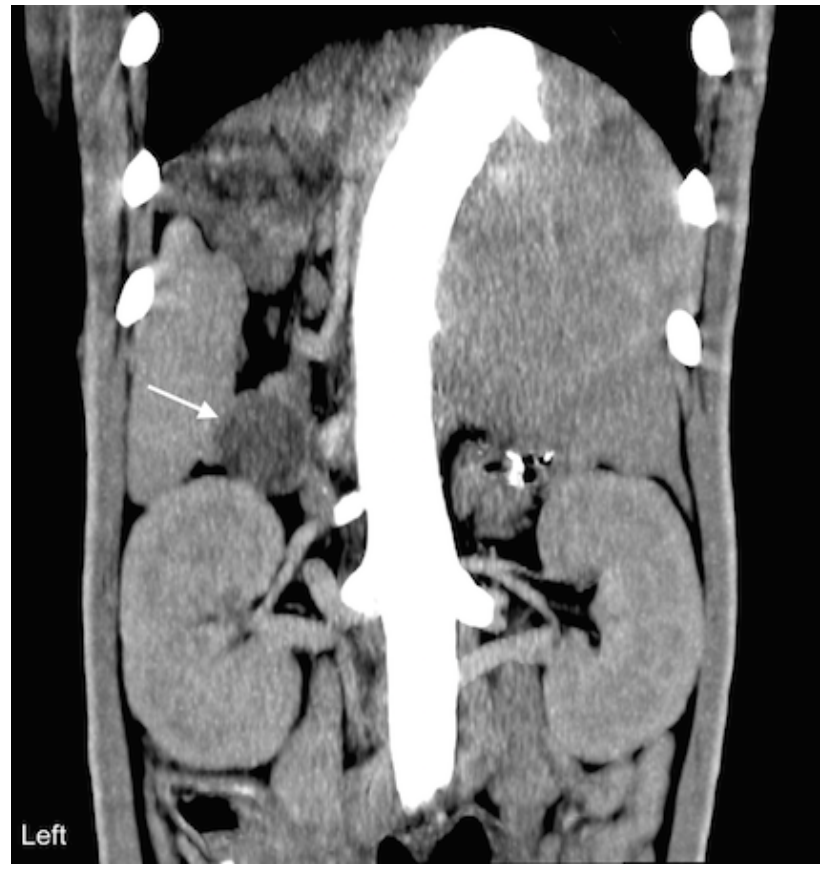

Figure 3. Fine-needle aspiration biopsy of the adrenal mass: on an hematic background, two large, single, round cells are detectable. These cells are characterized by a mild anysocytosis and by indistinct cell borders, abundant slightly basophilic and microvacuolized cytoplasms with small, central/paracentral, round, nucleus with clumped chromatin and a prominent nucleolus. May Grünwald-Giemsa stain, $100 \mathrm{X}$ magnification, $B a r=30 \mu \mathrm{m}$.

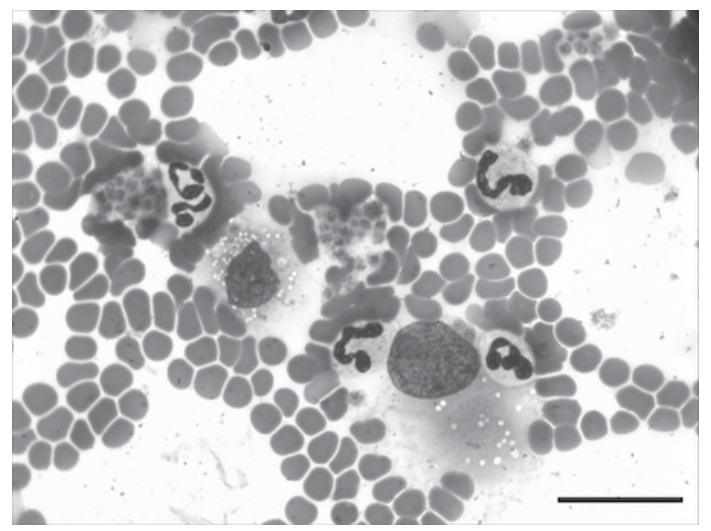

Figure 4. Fine-needle aspiration biopsy of the liver: hepatocytes are detectable on a hematic background. The three hepatocytes on the right do not show evident abnormalities, except for small, scattered vacuoles and fine pigment intracytoplasmic granulation. The three hepatocytes on the left, on the contrary, have a cytoplasmic rarefaction, characterized by prominent vacuoles of different size and shape, consistent with a degenerative hepatopathy. May Grünwald-Giemsa stain, 100X magnification, $B$ ar $=30 \mu \mathrm{m}$.

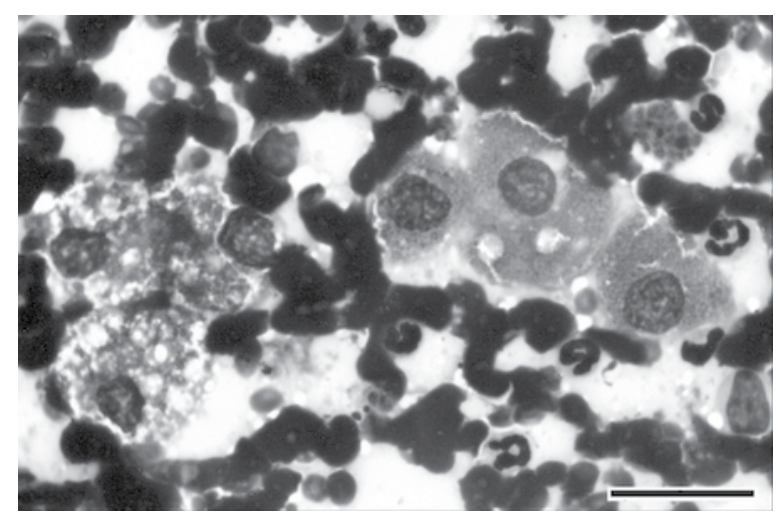


reference intervals have a wide range of variability both within and between patients, often exceeding the normal reference interval provided by the laboratory [1]. Reference intervals for both neutered female and male dogs range between 4.46-12.03 $\mathrm{ng} / \mathrm{dL}$ [1], while in the domestic female cat they reach $1.17 \mathrm{ng} /$ $\mathrm{dL}$ at the baseline level and nearly $2 \mathrm{ng} / \mathrm{dL}$ during the peak of the follicular phase [2] and in the intact male cat $0.95 \pm 0.12$ $\mathrm{ng} / \mathrm{dL}$ [3]. Considering that estradiol concentrations reported in human males are between 1.5-6 $\mathrm{ng} / \mathrm{dL}$ and in adult women during ovulatory peak reach $8.97 \mathrm{ng} / \mathrm{dL}$ [4], values recorded in our patient appeared markedly high. Further studies aimed to establish reference intervals in this species are needed to estimate the magnitude of these changes recorded in this patient.

Interestingly, there are several papers in veterinary literature reporting excess sex hormone production from a functional adrenal neoplasia in feline patients [5-9], even if adrenal tumours account for only $0.2 \%$ of all feline neoplasms [10]. Functional adrenal tumours are characterized by overproduction of aldosterone, cortisol, sex hormones and a typical cortical origin, while pheochromocytomas are non-functional medullary neoplasm [10]. Recently, a cyclic estrous-like behaviour in a female spayed cat has been reported, due to sex-hormone production by an adrenocortical secreting tumour [5]. In this case estradiol baseline concentration was high reaching $9.72 \mathrm{ng} / \mathrm{dL}$, clinical signs were progressively worsening and the right adrenal gland appeared increased in size $(1.03 \mathrm{~cm})$, while the contralateral gland was reduced in size, as occurred in our patient. Results from histopathology for this case revealed a large nodular lesion replacing the normal adrenal architecture, compatible with an adrenocortical carcinoma. The overproduction of sex hormones rather than cortisol from hyperadrenocorticism is reported to be very common in ferrets, in which adrenocortical adenomas account for $15-65 \%$ of the cases [11]. Other authors [12] reported the association between pathological and tomographic findings of adrenal neoplasms in 17 dogs. These authors remark that pheochromocytomas are more characterized by vascular invasion to the adjacent vessels and both pheochromocytomas and adenocarcinomas are described to invade the peripheral capsule of the adrenal glands and the surrounding adipose tissue. Contrary to malignant tumours, adrenal adenomas seem to be more circumscribed with defined margins, because they usually display a pseudo-capsule around the nodular lesion, with peripheral contrast enhancement and absence of adjacent vascular invasion, as in our case (Figure 1-2). Functional adrenal tumours are common in dogs and rare in cats $[5,13]$. These neoplasms in feline patients can be diagnosed as adenocarcinomas (50\%) or adrenocortical adenomas (50\%) [5]. The majority of these tumours induce an overproduction of adrenal hormones alone or in combination, such as glucocorticoids, mineralocorticoids (aldosterone) or sex hormones (estradiol, testosterone, progesterone) [5]. Although in our case no histopathology was performed before the surgery, considering that the lesion identified on the left adrenal gland showed a peripheral contrast enhancement with hypo-attenuating content, absence of vascular invasion and involvement of the adipose tissue surrounding the adrenal gland, absence of hypertension during the anaesthesia possibly referable to a pheochromocytoma, thus supporting a presumed diagnosis of a secreting adrenal adenoma. In humans, feminizing adrenal tumours (FATs) are rare, prevailing in males with clinical signs of gynecomastia and hypogonadism [14]. To the author's knowledge, no peer-reviewed description of a functional secreting adrenal adenoma in a lion, causing feminization of the patient, has ever been published before.

\section{References}

[1]. Frank LA, Mullins R, Rohrbach BW (2010) Variability of estradiol concentration in normal dogs. Vet Dermatol 21(5): 490-493.

[2]. Shille VM, Lundstrom KE, Stabenfeldt GH (1979) Follicular function in the domestic cat as determined by estradiol-17 beta concentrations in plasma: relation to estrous behavior and cornification of exfoliated vaginal epithelium. Biol Reprod 21(4): 953-963.

[3]. Müllera G, Martino-Andradea AJ, Santosa AS, Reghelina AL, Garciaa DM, et al. (2012) Testicular testosterone: Estradiol ratio in domestic cats and its relationship to spermatogenesis and epididymal sperm morphology. Theriogenology 78(6): 1224-1234.

[4]. Weilenmann R, Arnold S, Dobeli M, Rusch P, Zerobin K (1993) Estradiol and progesterone concentrations in the plasma of nonpregnant bitches during the sexual cycle. Schweiz Arch Tierheilkd 135(2): 51-57.

[5]. Meler EN, Scott-Moncrieff CJ, Peter AT, Bennett S, Ramos-Vara J, et al. (2011) Cyclic estrous-like behaviour in a spayed cat associated with excessive sex-hormone production by an adrenocortical carcinoma. J Feline Med Surg 13(6): 473-478.

[6]. Briscoe K, Barrs VR, Foster DF, Beatty JA (2009) Hyperaldosteronism and hyperprogesteronism in a cat. J Feline Med Surg 11(9): 758-762.

[7]. Millard RP, Pickens EH, Wells KL (2009) Excessive production of sex hormones in a cat with adrenocortical tumor. J Am Vet Med Assoc 234(4): 505-508.

[8]. DeClue AE, Breshears LA, Pardo ID, Kerl ME, Perlis J, et al. (2005) Hyperaldosteronism and hyperprogesteronism in a cat with an adrenal cortical carcinoma. J Vet Intern Med 19(3): 355-358.

[9]. Boag AK, Neiger R, Church DB (2004) Trilostane treatment of bilateral adrenal enlargement and excessive sex steroid hormone production in a cat. J Small Anim Pract 45(5): 263-266.

[10]. Daniel G, Mahony OM, Markovich JE, Appleman E, Monaghan KN, et al. (2015) Clinical findings, diagnostics and outcome in 33 cats with adrenal neoplasia (2002-2013). J Feline Med Surg.

[11]. Rosenthal KL, Peterson ME (1996) Evaluation of plasma androgen and estrogen concentrations in ferrets with hyperadrenocorticism. J Am Vet Med Assoc 209(6): 1097-1102.

[12]. Gregori T, Mantis P, Benigni L, Priestnall SL, Lamb CR (2015) Comparison of computed tomography and pathologic findings in 17 dogs with primary adrenal neoplasia. Vet Radiol Ultrasound 56(2): 153-159.

[13]. Bertazzolo W, Didier M, Gelain ME, Rossi S, Crippa L, et al. (2014) Accuracy of cytology in distinguishing adrenocortical tumors from pheochromocytoma in companion animals. Vet Clin Pathol 43(3): 453-459.

[14]. Chentli F, Bekkaye I, Yahiaoui S, Souidi S, Fedala NS, et al. (2013) Feminizing adrenal tumors: Our experience about three cases. Indian J Endocrinol Metab 17(3): 509-513. 